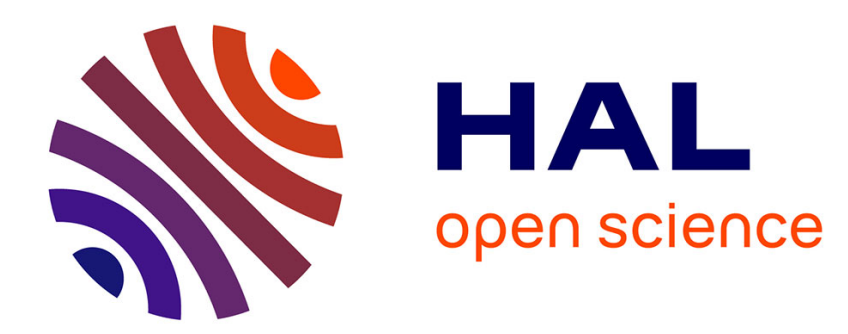

\title{
From one community to many: how novel objects in the crop protection field reveal epistemic boundaries
}

\author{
Antoine Blanchard
}

\section{To cite this version:}

Antoine Blanchard. From one community to many: how novel objects in the crop protection field reveal epistemic boundaries. Social Epistemology, 2016. halshs-01242705

\section{HAL Id: halshs-01242705 \\ https://shs.hal.science/halshs-01242705}

Submitted on 13 Dec 2015

HAL is a multi-disciplinary open access archive for the deposit and dissemination of scientific research documents, whether they are published or not. The documents may come from teaching and research institutions in France or abroad, or from public or private research centers.
L'archive ouverte pluridisciplinaire HAL, est destinée au dépôt et à la diffusion de documents scientifiques de niveau recherche, publiés ou non, émanant des établissements d'enseignement et de recherche français ou étrangers, des laboratoires publics ou privés. 


\title{
From one community to many: how novel objects in the crop protection field reveal epistemic boundaries
}

\author{
Antoine Blanchard* \\ antoine.blanchard@gmail.com
}

\begin{abstract}
In this paper, I present a case study in the field of crop protection and discuss its epistemological implications. Through the advent of a novel class of objects at the end of the 1970s in Europe and the USA, namely plant elicitors that trigger the plant's own defence reactions, we witness how dissent between epistemic communities appears where assimilation had been the rule. The convergence between the industry and the academia as a coherent "phytosanitary universe", despite the fact that they are made of several epistemic communities, is put to the test by plant elicitors, which do not fit exactly within existing categories. The plasticity of plant elicitors who can serve both as epistemic things and technical objects (Rheinberger 1997) does not suffice to qualify them as boundary objects bridging diverging communities. In particular, the specific arrangement of epistemic communities that they reveal can be described as Matryoshka dolls. This empirical account provides a fresh look at the relation between physical objects and epistemic boundaries, as well as the configuration of epistemic communities.
\end{abstract}

Keywords: agricultural science, agrochemical, boundary object, crop protection, epistemic culture

\footnotetext{
* IRIST, Université de Strasbourg, 7 rue de l'Université, F-67000 Strasbourg, France Current affiliation: Deuxième labo, 56 bd Auguste Blanqui, F-75013 Paris, France
} 
It is generally considered that objects of science can serve as a "source of assimilation between epistemic cultures" (Kestenhofer 2007, 367), either because they are transferred from one culture to the other or because they emerge at the boundary between communities. However, an empirical research project conducted over the course of four years on plant elicitors illustrates how emerging objects can also trigger open dissent and reveal epistemic boundaries that were dissimulated. This research draws on a series of sixteen interviews with diverse actors (including eight academic researchers in diverse fields, two former researchers in the industry who are now senior managers and one agricultural scientist from a technical institute counselling organic farmers), mostly located in France, as well as quantitative and qualitative examination of scientific publications (including research articles, patents and specialized press). I present here some central results of this case study, which will be published elsewhere in full, and discuss its epistemological implications.

While epistemic cultures sensu stricto "constitute specific ways of producing knowledge as well as relating to that which is not known and uncertain" (Kastenhofer 2007, 360), this article extends the definition to all ways of dealing with knowledge and includes the production of commodities using scientific and technical knowledge. It follows that epistemic communities are groups of individuals who share an epistemic culture sensu lato.

\section{Before plant elicitors: a coherent phytosanitary universe}

The French crop protection industry has been thriving since the beginning of the 20th century, when a very active propaganda started to promote the use of arsenicals and such (Fourche 2004). As a massive plague of Colorado beetles infested potato crops in the 1920s and 1930s, subventions were given to the farmers who would use chemicals (Jas 2007, 371-372). Since then, the crop protection products have evolved, as well as the agricultural landscape and imperatives, but they still display a picture where everyone's interests are interwoven. In particular, the co-evolution between the agrochemical industry and the public research sector has led to a situation where each one performs well bounded tasks while, at the same time, converging to build one same phytosanitary universe. I coin this phrase to include the communities working to develop and apply better crop protection products, said products and rules on what constitutes a good crop protection product, and the arenas where these regulatory, technical and scientific matters are discussed. It comprises two main paradigms or "schools of thought": chemical control and biological control, which will be described later. This universe includes the authorities, which need experts to agree on the definition and measurement of an "active ingredient" and a "safe use". It also includes the farmers, who want better chemicals yielding results rather than sterile controversies. Agronomy engineers trained close to the industry and holding PhDs can be found doing research in the public sector. In some people's eyes, this could look like a conspiracy (van den Bosch 1978), where research freedom is lost and the interest of the public ignored. However, the following analysis shows how such co-construction is possible.

Typically, the agrochemical industry discovers new active ingredients through the massive screening of candidate substances (Ridley et al. 1998). Then, it "designs" the best molecule possible by exploring and testing various structures and combinations. Once the compound is shown to be safe and perform better than its predecessors, public research labs may come in to clarify its mode of action: what is its molecular target? How does it interfere with the organism's metabolism? Such collaborations with the industry help fund academic research and often shed new lights on the biology of pathogens or pests (in the case of fungicide and insecticide compounds) or plants (in the case of herbicides). Agronomic strategies to prevent resistance to the new compound can then be developed in the interest of the industry but also the farmers.

Such a public research lab in France, belonging to the Institut national de la recherche agronomique 
(Inra) in Versailles and specialized in the study of fungal pathogens and fungicides, was described by its director as comprising two biologists (agricultural scientists by training, one specialized in population genetics, the other with broad skills in biology) and several molecular biologists and biochemists (including a former organic chemist). According to the lab head, these biologists are interested in the visible traits of the fungi (the phenotype) while the molecular biologists help uncover the genetic basis of these traits (the genotype) and the biochemists work at the interface between the two. Such cooperation is only possible because they share the same heuristic system, asking complementary questions using compatible laboratory techniques at similar biological scales, which they would not share with an ecosystem ecologist (Kastenhofer 2007, 366). Historically, the activities of this research lab evolved from the study of dose-response relationships and the metabolism of crop protection products after World War II, into researching their mode of action and the biochemical and genetic mechanisms behind resistance to these compounds after the 1970s (Inra 1996, 65) — thus integrating a wider range of skills and biological levels. By convening various disciplines and expertise, this laboratory allowed the integration of individuals and later assimilation, to build up convergence between epistemic cultures (Kastenhofer 2007, 366). In the lab head's own words, the main driver for this evolution was "to accompany the pesticides industry" (personal communication, July 20, 2007).

The "convergence between basic and applied research, public and private research, and between science and technology" (Kastenhofer 2007, 366) continues with small and medium enterprises (SMEs such as Biorizon, Staphyt, Biotransfert), mostly independent research labs, which perform the assessment of pesticides before their approval by the authorities and monitor the possible apparition of resistances once commercialized. They provide certified services using standard techniques that are agreed upon by the industry, academic research labs and the authorities. As all the other actors, they move seamlessly inside the network of interwoven interests and convergent epistemic cultures. However, this convergence can be put to the test and the underlying boundaries exposed when a novel object supporting new approaches to pest management arises, as plant elicitors will show.

Unlike biological control (the use of biological agents and "natural" chemicals to protect crops) that has been around for more than a century (Jourdheuil, Grison, and Fraval 1991), plant elicitors emerged at the end of the 1970s and, at first, seemed to fit into the main paradigm of crop protection (so-called chemical control). With a novel mode of action that helps the plant to defend itself rather than targeting the pest or pathogen, these objects can be synthetic or natural and could have retained most of the characteristics of their predecessors. Instead, as we will see, this tiny difference proved to impact entrenched positions and forced actors to take a stance on plant elicitors.

\section{Plant elicitors as epistemic things and technical objects}

In his book Toward a history of epistemic things, Rheinberger (1997) draws a distinction between epistemic things and technical objects. The former are parts of the material world that are subjected to the enquiry of the scientists. The latter are "technical routines the experimenter can largely take for granted" (Bloor 2005, 289). This distinction is said to be "functional rather than structural" (Rheinberger 1997, 30) and we could not agree more as far as our plant elicitors are concerned. Depending on where they stand, they are seen as either epistemic things or technical objects. For instance, the active ingredient laminarin can alternatively be studied as part of research and development projects (Aziz et al. 2003), or be used as a control to uncover the mechanism of lipopolysaccharides-induced defence response (Desender et al. 2006). In the former case they have yet to be characterized, in the latter they are tools used to investigate related biological mechanisms. Their case is never closed and being featured as a technical object doesn't mean that they reached "a 
state in which the relation between concept and object is no longer problematic" (Rheinberger 2005, 407). As they are constantly re-negotiated and new concepts are applied onto them, they exhibit a polysemy that definitely is "a motor of knowledge acquisition" (Rheinberger 2005, 408).

Their plasticity could help plant elicitors pervade the phytosanitary universe and weave into existing networks. However, as I will show, this feature alone is not enough to build consensus. As technical objects, they enter the production chain of either large firms or SMEs depending on whether they are chemical compounds or plant extracts; as epistemic things they are torn between molecular academics and engineers.

\section{After plant elicitors: epistemic communities revealed}

What plant elicitors reveal is a series of epistemic communities that had become dissimulated as the result of the assimilation process - and which, rather than being simply juxtaposed, are nested in each other. The first of these epistemic boundaries separates academia from industry. In their study of innovation in the pesticide industry, Achilladelis, Schwarzkopf, and Cines $(1987,209)$ show that between 1930 and 1980, "the success of these leading firms [of the agrochemical sector] was related to their capacity to assimilate and develop the results of fundamental research in chemistry". Academic and industry research would exchange knowledge and know-how, drawing from the same set of expertise and aiming at the same advances. Chemists in both environments would share a common background and culture, often meeting at professional conferences such as the International Plant Protection Congress regularly convened in Glasgow, UK. They would even boast an authoritative claim to policy-relevant knowledge as in Peter Haas' definition of an "epistemic community" (Haas 1992). But this is different with plant elicitors. They emerged in academic research as part of the broader agenda of phytopathology aimed at understanding the relations between plants and their pathogens. From the early descriptive research of Carlo Arnaudi (1933) to the genetic studies reviewed by Glazebrook, Rogers, and Ausubel (1997), there is one coherent progression toward understanding the basis of plant defence reactions and making the myth of plant immunization come true (Lucas 1999). Plant elicitors, as "vaccines for plants", were an objective of this agenda but also enabled more research. For the industry, on the other hand, they departed clearly from a long practice of chemical research. A first boundary is thus revealed between two communities, academia and the industry having differing capacities to accommodate this novel object.

However, another boundary appears when zooming in on the industry. The portrait drawn by Achilladelis, Schwarzkopf, and Cines (1987) focused on leading firms but did not account for SMEs. Even though most of them participate in the same phytosanitary universe, they can take a different stance on plant elicitors. Contrary to larger agrochemical firms, they are not locked in a "'one problem-one solution' cognitive framework", where "the organisation of knowledge and research teams is focused on specific problems and not on interactions within crop systems" and "interactions between chemical compounds, specific plant varieties and crop systems are barely considered" (Joly and Lemarié 2002, 162). They do not obey to the model of the research-intensive start-up either, as their limited resources carry out the entire development chain - from research to the commercialization of products (Lemarié, Jorge, and Joly 2001, 17). As a consequence, the many SMEs working on plant elicitors like Tribo Technologies or Biophytech in France depend on public research for the discovery and testing of new products and need to maintain very close ties with it. As Tribo Technologies claimed on their website ${ }^{1}$ : "The work conducted by development firms like Tribo Technologies, in partnership with officials, researchers and retail professionals, shows a promising way for the future of crop protection." On the opposite, the small number of

\footnotetext{
${ }^{1}$ http://www.semafort.com/page3.html accessed December $14^{\text {th }}, 2007$.
} 
agrochemical firms working on plant elicitors have started to shift away from academia, as "the rapid advance of [their] knowledge of the molecular mechanisms underlying the biological and chemical resistance activation in plant" enables a more rapid and reliable discovery and development of plant elicitors by in-house research teams (Leadbeater and Staub 2007, 241). As to the fact that plant elicitors have been well represented in the French professional monthly magazine Phytoma for the period 1990-2007 comparatively to their market share (Fig. 1), it results from articles authored by public research labs and SMEs only. While big agro companies usually publish in Phytoma, they did not participate in this effort toward plant elicitors, thus revealing a demarcation that laid hidden.

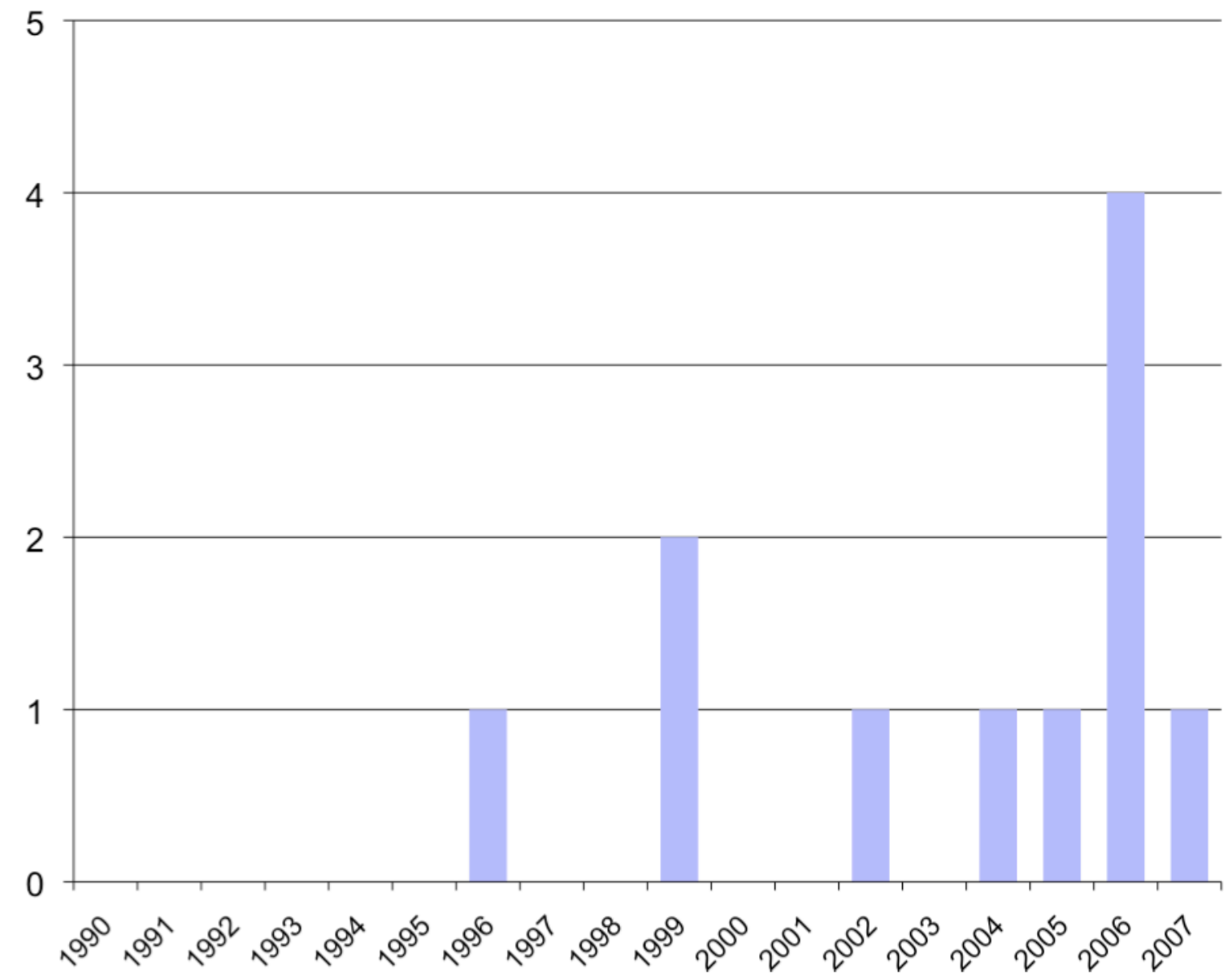

Figure 1: Number of articles on plant elicitors published annually in the professional magazine Phytoma, ranging between 0 and 4 out of an average of 121 articles per year.

Global agrochemical companies are also torn between two epistemic cultures. Unlike the many SMEs involved in plant elicitors, very few of them invested in this technology - Syngenta, formerly Ciba-Geigy, being one of the rare cases. In 1975, the mechanisms of systemic acquired resistance (SAR) in plants were not well understood and few people believed that a single mechanism explained all plant defence responses. Joseph Kuć was one of them and a conference presentation he gave that year was attended by Theodor Staub, who brought many insights and much interest back to Ciba-Geigy in Switzerland (den Hond 1998). However, in the 1970s, the research agenda of the industry was overloaded with newcomers like systemic fungicides and "natural products" such as phytoalexins. Ciba-Geigy, among the largest and most successful agrochemical companies at the time, was one of the few players who could afford supporting yet another research project - based on very speculative grounds - albeit at a low investment level at first (den Hond 1998). Such endeavor was not easy as most of its R\&D was focused on chemistry and it took a team of biologists to unravel the mechanisms of SAR induction, develop screening 
tests and find candidate compounds. This was achieved after years of intense biological research, in collaboration with Joseph Kuć at the University of Lexington (Kentucky, USA), and as a result, a patent application was filed for acibenzolar-S-methyl (Bion $\left.{ }^{\circledR}\right)$ in 1987. Although it resulted from outstanding work using "novel screening techniques, utilizing molecular biology" (Gullino, Leroux, and Smith 2000,1), Bion ${ }^{\circledR}$ was quickly normalized when it entered the downstream production chain. Indeed, the work on its synthesis followed the canon of chemistry (Fig. 2) and it is currently manufactured like any other active ingredient. Going forward, Bion ${ }^{\circledR}-$ related activities, "as in conventional chemical crop protection, (...) will focus on finding other molecules, with further adapted environmental and toxicological characteristics, even lower dose rates, alternative selectivity, and different crop spectrum" (Tally et al. 1999). Because chemistry and biology weight differently in the agrochemical industry, the discovery of a plant elicitor like Bion ${ }^{\circledR}$ would have been impossible without the combination of personal conviction, a favorable economical context and downstream normalization of the compound through chemistry. Conversely, elicitors less prone to be seen as pure chemical compounds fail in the hands of the big agrochemical companies, as was the case of the plant extract Milsana ${ }^{\circledR}$, discovered in 1987 by a German research lab partnering with BASF and introduced in 1993. Milsana ${ }^{\circledR}$ could not be reduced to a single active ingredient and, as a plant extract, it was soon handed over to BASF's subsidiary on the consumer lawn and garden market, Compo, and later split between two SMEs: Dr. Schaette AG in Europe, KHH BioSci Inc. in North and South America.

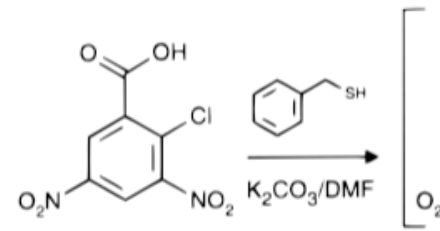

11

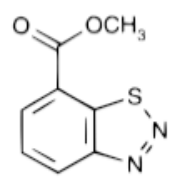

2

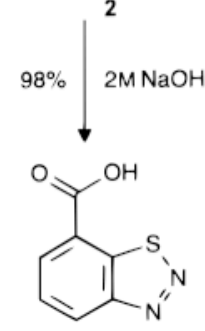

3

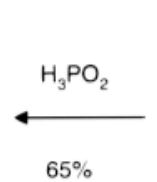

$65 \%$

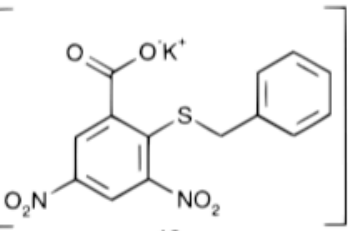

12

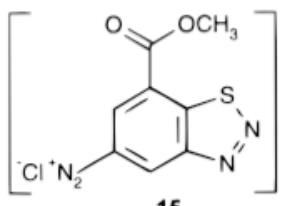

15
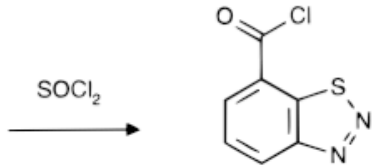

16

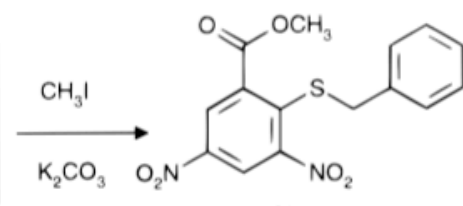

13

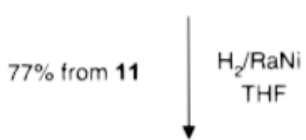

$\mathrm{NaNO}_{2} / \mathrm{H}^{+}$<smiles>COC(=O)c1cc(N)cc(N)c1SCc1ccccc1</smiles>

14

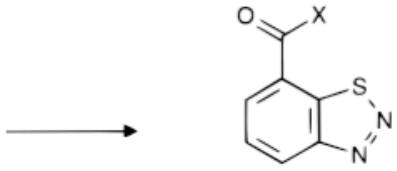

17

Figure 2: Synthesis of benzo[1,2,3]thiadiazole-7-carboxylic acid derivatives, including Bion®: one of the many pathways proposed by Kunz, Schurter, and Maetzke (1997).

Coming back to academia, two epistemic cultures are concerned by plant elicitors: molecular biology and agronomy. The former rests on in vitro and in vivo experimental systems, using a reductionist approach while the latter is complexity oriented, using a systems approach and in situ observations and experiments (Kastenhofer 2007, 361). Historically, plant elicitors have been the privilege of molecular biologists in the lab, even though agronomists - and before them, growers and practitioners - had conceptualized in their own way how the habit of spreading seaweed on crops (e.g. on the coasts of Brittany) impacted their health and defence reactions. Molecular biologists made plant elicitors as we know them today, whose properties depend on controlled 
conditions, but there is a growing awareness that the other end of the chain of interests must also be covered (Lyon et al. 2007). After molecular biology secured the interest of research institutes and achieved high profile publications, agricultural research was asked to translate them into actual crop protection strategies. It is in a unique position to obtain research contracts and make allies in the agricultural sector, like a team in Dijon did with champagne producer Moët et Chandon.

Interestingly enough, the two communities are linked through the materiality of plant elicitors that circulate between them. The co-authorship network in Fig. 3 shows how J.-M. Joubert (in the center) connects the groups on the left hand-side (molecular biologists from Strasbourg and Roscoff) and the right hand-side (agronomy researchers from Reims and Dijon, both wine regions). Indeed, Joubert works at Goëmar, the small firm that owns the active ingredient laminarin all of them study and supplies it to them. This connection serves as evidence that, in some cases, plant elicitors do bridge the epistemic communities they helped delineate.

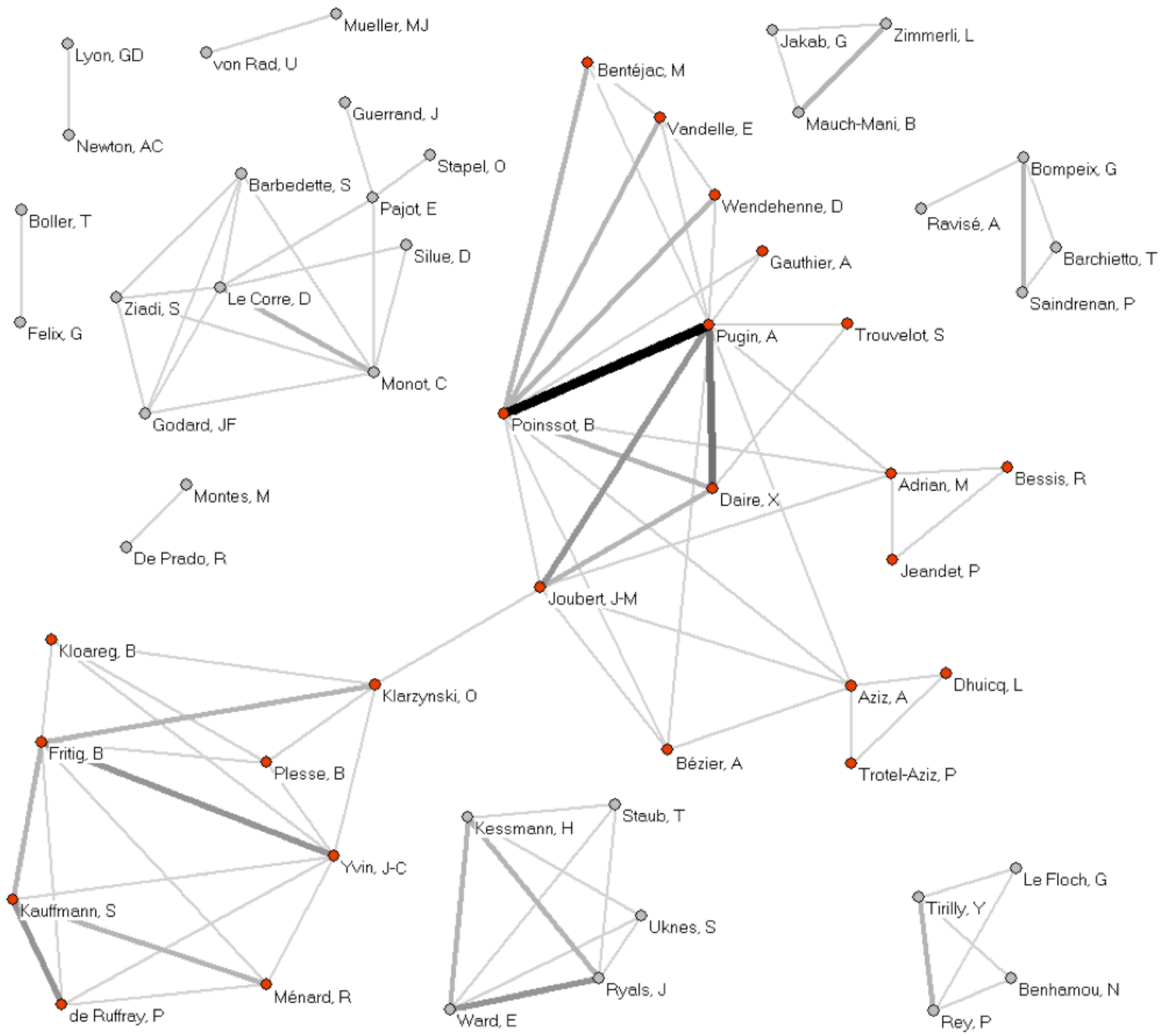

Figure 3: Co-authorship network based on a collection of 148 references from the international scientific literature on plant elicitors (1951-2007). The researchers mentioned in the text are shown in red and the thickness of the edge reflects the intensity of the collaboration (between 2 and 7 co-authored publications).

However, even among agronomy researchers, plant elicitors reveal epistemic boundaries in between engineers and academics. France maintains a strong distinction between the two, as engineers are trained in elite "grandes écoles" and pure academics are trained in universities. In agronomy, engineers have a systems approach and look for solutions to the farmers' needs (Bonneuil 2006) 
while academics want causal relationships and value the accumulation of knowledge. The main public research institute for agronomy in France, Inra, has a large proportion of engineers holding PhDs and working as researchers (more than 30\% in the "Plant health and environment" department according to our calculations) whereas those are hardly present in university labs. It is surprising that the agronomy researchers cited above are almost exclusively university scientists. I posit that when reaching out to agronomy, molecular biologists focused on university labs near them, and that researchers with a background in engineering failed to "see" or accept this novel object: the novel crop protection concepts it conveyed and the new use cases it promoted questioned too much past and current practices.

\section{Conclusion: epistemic communities and scientific objects}

This case study shows that scientific objects are not necessarily a source of assimilation between epistemic cultures and can be a source of dissension. Such are plant elicitors, which exposed boundaries between contrasting communities, which were aligned until a novel object put them to the test and made them realize that they wanted something different for it. Once visible, these epistemic communities appear nested like Matryoshka dolls rather than merely juxtaposed; from the higher (academia vs. industry) to the lower level (engineers vs. academics), each level will have its own stance based on different criteria (see Fig. 4). I posit that this result can be generalized: when diverging mind-sets are opposed on a given topic, some of these mind-sets will be found within each other and the higher level will be irreducible to the sum of its parts.

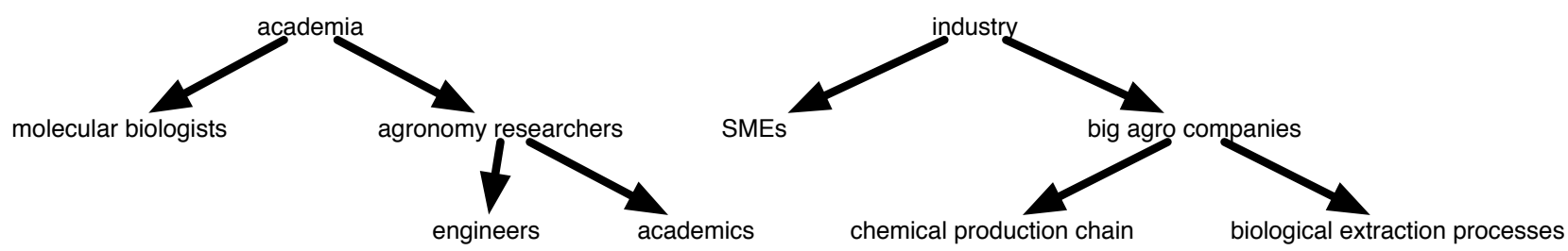

Figure 4: Tree diagram of nested epistemic communities as revealed by plant elicitors.

What does it tell us of plant elicitors' failure on the market? Following Star and Griesemer (1989), sociologists of science took on the notion of boundary objects to emphasize how some entities can be plastic enough to inhabit different communities, yet robust enough to maintain a shared identity. Their case studies focused on communities belonging to different "social worlds" that hardly intersect (typically amateurs vs. professionals). Plant elicitors could have served as a boundary object to bridge diverging communities. However, while they do connect molecular biologists (aligned with research institutes) and agronomy researchers (aligned with the agricultural sector) as in Fig. 3, they fail to bridge academics and engineers, the industry and academia, SMEs' and big agro companies, chemical production chains and biological extraction processes.

\section{Acknowledgements}

I am grateful to the reviewers whose comments helped improve earlier versions of this article, and to Soraya Boudia who supervised the MSc thesis on which this article is based. All responsibility for the argument and any errors that may remain are of course mine alone. 


\section{References}

Achilladelis, Basil, Albert Schwarzkopf, and Martin Cines. 1987. "A study of innovation in the pesticide industry: Analysis of the innovation record of an industrial sector." Research Policy 16: $175-212$.

Arnaudi, Carlo. 1933. "On the vaccination of the tobacco plant against Thielaviopsis basicola." Bulletin of the Torrey Botanical Club 60: 583-597.

Aziz, Aziz, Benoît Poinssot, Xavier Daire, Marielle Adrian, Annie Bézier, B. Lambert, Jean-Marie Joubert, and Alain Pugin. 2003. "Laminarin elicits defense responses in grapevine and induces protection against Botrytis cinerea and Plasmopara viticola." Molecular Plant-Microbe Interactions 16: 1118-1128.

Bloor, David. 2005. "Toward a sociology of epistemic things." Perspectives on Science 13: 285312.

Bonneuil, Christophe. 2006. "Cultures épistémiques et engagement public des chercheurs dans la controverse OGM." Natures Sciences Sociétés 14: 257-268.

Den Hond, Frank. 1998. "Systemic acquired resistance: A case of innovation in crop protection." Pesticide Outlook 9: 18-23.

Desender, Sabine, Olivier Klarzynski, Philippe Potin, Marie-Renée Barzic, Didier Andrivon, and Florence Val. 2006. "Lipopolysaccharides of Pectobacterium atrosepticum and Pseudomonas corrugata induce different defence response patterns in tobacco, tomato, and potato." Plant Biology 8: 636-645.

Fourche, Rémi. 2004. "Contribution à l'histoire de la protection phytosanitaire dans l'agriculture française (1880-1970).” PhD diss., Université Lumière de Lyon.

Glazebrook, Jane, Elizabeth E. Rogers, and Frederick M. Ausubel. 1997. "Use of Arabidopsis for genetic dissection of plant defense responses." Annual Review of Genetics 31: 547-569.

Gullino, Lodovica L., Pierre Leroux, and Constance M. Smith. 2000. "Uses and challenges of novel compounds for plant disease control." Crop Protection 19: 1-11.

Peter M. Haas. 1992. "Epistemic Communities and International Policy Coordination." International Organization 46: 1-35.

Inra. 1996. Chronique du centre de recherches de Versailles. Versailles: Centre de recherches de Versailles.

Jas, Nathalie. 2007. "Public health and pesticide regulation in France before and after Silent Spring." History and Technology 23: 369-388.

Joly, Pierre-Benoit, and Stéphane Lemarié. 2002. "The technological trajectories of the agrochemical industry: Change and continuity." Science and Public Policy 29: 259-266.

Jourdheuil, Pierre, Pierre Grison, and Alain Fraval. 1991. "La lutte biologique : un aperçu historique." Le Courrier de la Cellule Environnement de l'Inra 15: 37-60.

Kastenhofer, Karen. 2007. “Converging epistemic cultures?” Innovation: The European Journal of Social Science Research 20: 359-373.

Kunz, Walter, Rolf Schurter, and Thomas Maetzke. 1997. "The chemistry of benzothiadiazole plant activators." Pesticide Science 50: 275-282.

Leadbeater, Andy, and Theo Staub. 2007. "Exploitation of induced resistance: A commercial perspective." In Induced Resistance for Plant Defence: A Sustainable Approach to Crop Protection, edited by Dale Walters, Adrian C. Newton, and Gary D. Lyon, 229-242. Oxford: Blackwell. Lemarié, Stéphane, Isabelle Jorge, and Pierre-Benoît Joly. 2001. SMEs in the French agrochemicals, seeds and plant biotechnology industries. Annex D3 to PITA Project: Policy influences on technology for agriculture: Chemicals, biotechnology and seeds. Final report, edited by Joyce Tait, Joanna Chataway and David Wield. http://technology.open.ac.uk/cts/pita/AnnD3SMEs-FR.pdf

Lucas, John A. 1999. "Plant immunisation: From myth to SAR." Pesticide Science 55: 193-196. Lyon, Gary D., Adrian C. Newton, and Dale Walters. 2007. "Induced resistance in crop protection: The future, drivers and barriers." In Induced resistance for plant defence: A sustainable approach 
to crop protection, edited by Dale Walters, Adrian C. Newton, and Gary D. Lyon, 243-249. Oxford: Blackwell.

Rheinberger, Hans-Jörg. 1997. Toward a history of epistemic things: Synthesizing proteins in the test tube. Stanford: Stanford University Press.

Rheinberger, Hans-Jörg. 2005. "A reply to David Bloor: 'Toward a sociology of epistemic things'." Perspectives on Science 13: 406-410.

Ridley, Stuart M., Clare A. Elliott, Mabel Yeung, and David Youle. 1998. "High-throughput screening as a tool for agrochemical discovery: Automated synthesis, compound input, assay design and process management." Pesticide Science 54: 327-337.

Star, Susan Leigh, and James R. Griesemer. 1989. "Institutional ecology, 'translations' and boundary objects: Amateurs and professionals in Berkeley's Museum of Vertebrate Zoology, 19071939." Social Studies of Science 19: 387-420.

Tally, Allison, Michael Oostendorp, Kay Lawton, Theo Staub, and Bobby Bassi. 1999. "Commercial development of elicitors of induced resistance to pathogens." In Induced plant defences against pathogens and herbivores, edited by Anurag A. Agrawal, Sadik Tuzun, and Elizabeth Bent, 357-369. St Paul, MN: American Phytopathological Society Press.

Van den Bosch, Robert. 1978. The Pesticide Conspiracy. Garden City, NY: Doubleday. 